\title{
MAX WEBER E A RECEPÇÃO DO DIREITO ROMANO
}

\author{
MAX WEBER AND THE RECEPTION OF ROMAN LAW
}

\section{MAX WEBER Y LA RECEPCIÓN DEL DERECHO ROMANO}

\begin{abstract}
AleXANDER DE CASTRO
Doutor em Direito pela Universidade de Florença (Itália). Pós-doutorado pelo Instituto de História do Direito da Westfälische Wilhelms-Universität Münster (Alemanha) e pela Freie Universität Berlin. Foi pesquisador visitante do Exzellenzcluster Regilion und Politik da Westfälische Wilhelms-Universität Münster e do Lateinamerika-Institut da Freie Universität Berlin. Professor no Centro Universitário de Maringá, CESUMAR, Brasil. (Maringá, Paraná, Brasil). http://lattes.cnpq.br/8837968472997490 / http://orcid.org/0000-0002-3316-2773 / alex.de.castro@hotmail.com
\end{abstract}

\section{RESUMO}

Max Weber aborda o tema da recepção do direito romano na Idade Média e Moderna europeia no âmbito de sua sociologia tipológico-comparativa do direito. Buscando definir as bases para a compreensão da singularidade do processo de racionalização ocidental - e, dentro dele, da racionalização do direito - a recepção aparece como um importante fator da produção das qualidades formais do moderno direito sistematicamente estatuído e aplicado por profissionais especializados, cuja marca principal é um racionalismo formal baseado na interpretação lógica do sentido. Esse racionalismo de abstração lógica, que acabou tornando-se a característica principal do trabalho jurídico moderno, foi o produto e o legado para a modernidade da jurisprudência do direito comum, desenvolvida a partir da recepção e dedicada à sistematização do direito romano recebido.

Palavras-chave: direito moderno; história do direito; recepção do direito romano; sociologia jurídica; Weber.

\begin{abstract}
Max Weber addresses the theme of the reception of Roman law in the European Middle Ages and Early Modern Period within his comparative-typological sociology of law. Seeking to lay the foundations for understanding the uniqueness of the process of Western rationalization - and, within it, the rationalization of law - the reception appears as an important factor in the production of the formal qualities of the modern systematically established and expertoperated law, whose main feature is its formal rationalism based on the logical interpretation of meaning. This logical abstract rationalism, which became the main characteristic of modern legal work, was the product and legacy for the modernity of the jurisprudence of ius commune, which started to be developed with the reception and was dedicated to the systematization of the received Roman law.
\end{abstract}

Keywords: modern law; legal history; reception of Roman law; legal sociology; Weber.

\section{RESUMEN}

Max Weber aborda el tema de la recepción del derecho romano en la Edad Media y Moderna europea en el marco de su sociología tipológico-comparativa del derecho. Buscando establecer las bases para la comprensión de la singularidad del proceso de racionalización occidental - y, dentro de él, de la racionalización del derecho - la recepción aparece como un importante factor de la producción de las cualidades formales del moderno derecho sistemáticamente estatuido y aplicado por los profesionales especializados, cuya característica principal es un racionalismo formal basado en la interpretación lógica del sentido. Este racionalismo de abstracción lógica, que se convirtió en la característica principal del trabajo jurídico moderno, fue el producto y el legado para la modernidad de la jurisprudencia del ius commune, que comenzó a desarrollarse con la recepción y se dedicó a la sistematización del derecho romano recibido.

Palabras clave: derecho moderno; historia del derecho; recepción del derecho romano; sociología jurídica; Weber. 


\section{SUMÁRIO}

INTRODUCCAO; 1 A RACIONALIZAÇÃO DO DIREITO: OBJETO DA INVESTIGAÇÃO SOCIOLÓGICA; 2 O LUGAR DA RECEPÇÃO NA SOCIOLOGIA DO DIREITO DE WEBER; 3 ELEMENTOS DA SOCIOLOGIA DO DIREITO DE WEBER PARA COMPREENDER O PROBLEMA DA RECEPÇÃO; 4 RECEPÇÃO DO DIREITO ROMANO E ABSOLUTISMO: A RACIONALIZAÇÃO DO DIREITO NA DOMINAÇÃO PRINCIPESCA PATRIMONIAL; CONCLUSÃO; REFERÊNCIAS.

\section{INTRODUÇÃO}

A contribuição de Max Weber para a elucidação das características fundamentais do direito moderno já foi posta em evidência por diversos juristas, filósofos, historiadores e sociólogos do direito. É conhecido também o fato de que o pai da sociologia - posto que Weber ocupada ao lado de Durkheim - realizou seus estudos formais nas ciências jurídicas e inclusive iniciou sua carreira acadêmica como professor da faculdade de direito da Universidade Humboldt de Berlin (à época, Friedrich-Wilhelms-Universität zu Berlin), antes de trilhar rapidamente o caminho da história e da economia até à sociologia. ${ }^{1}$ Entretanto, um importante aspecto da trajetória intelectual de Weber é frequentemente negligenciado até mesmo por especialistas em sua obra: Weber, em seus anos capitais de formação intelectual - isto é, da sua graduação ao doutorado e até a sua habilitação para a docência - foi fundamentalmente um historiador do direito.

A Escola Histórica do Direito - que havia sido fundada por Friedrich Carl von Savigny no contexto da polêmica sobre a codificação do direito civil dos Estados alemães durante a restauração pós-napoleônica - dominou as ciências jurídicas alemãs durante todo o século XIX, mas chagava aos estertores ao diluir-se na pandectística e preparar a insurgência do Código Civil alemão, que marcaria o seu declínio definitivo. Weber escreveu sua tese de doutorado sobre a história do direito comercial (especificamente sobre origens do princípio da responsabilidade solidária do direito comercial nas cidades italianas medievais) sob a orientação de um dos mais instigantes juristas-historiadores da época, o comercialista Levin Goldschmidt. Posteriormente,

\footnotetext{
${ }^{1}$ Ainda em 1917, Weber apresentava-se como economista ao iniciar a famosa conferência sobre $A$ Ciência como Vocação. WEBER, Max. A ciência como vocação. In: WEBER, Max. Ciência e Política: duas vocações. Tradução de Leonidas Hegenberg e Octany Silveira da Mota. 12. ed. São Paulo: Cultrix, 2004, p. 17-52. p. 17. Entretanto, pode-se afirmar que ele começa a ver-se cada vez mais como sociólogo já a partir de 1913. Veja-se LEPSIUS, M. Rainer. "Economia e sociedade": a herança de Max Weber à luz da edição de sua Obra completa (MWG). Tempo social: Revista de Sociologia da USP, São Paulo, v. 25, n. 1, p. 137-145, 2012. p. 140.
} 
ele ainda entregaria dois trabalhos histórico-jurídicos a fim de conseguir sua habilitação para a docência universitária: A história agrária romana em seu significado para o direito público $e$ privado e A história das sociedades comerciais na Idade Média, segundo fontes sul-europeias. ${ }^{2}$ Habilitou-se, assim, para lecionar direito comercial e direito romano em Berlin.

Um dos grandes temas do historicismo jurídico alemão no século XIX foi o significado da recepção do direito romano. De fato, o historicismo jurídico alemão subdividiu-se em duas grandes escolas de pensamento, tendo como ponto de divergência justamente a forma de responder a essa questão e, consequentemente, de conduzir todo o trabalho histórico-jurídico. Com seu manifesto anticodificação, Savigny reivindicava o estudo da história do direito enquanto manifestação do Volksgeist germânico como alternativa à codificação de inspiração supostamente cosmopolita e universalista forjada no iluminismo e pós-iluminismo francês. Assim surgia a escola de juristas que iria se dedicar à pesquisa da evolução histórica da ciência romanista do direito a fim de unificar cientificamente o direito alemão e colocar de lado a proposta de unificação legislativa pela codificação, sustentada por Anton F. J. Thibaut. Entretanto, alguns anos depois, Georg Beseler chamaria a atenção para a contradição em se procurar o "espírito do povo" alemão em um direito recebido de outro povo e inauguraria a linha germanista do historicismo jurídico alemão, contrapondo-se assim aos romanistas da escola de Savigny e Puchta.

Levin Goldschmidt, entretanto, via na história do direito comercial medieval uma possibilidade de conciliar - ao menos parcialmente - o romanismo e o germanismo jurídicos. De fato, os institutos de direito comercial desenvolveram-se no âmbito das práticas comerciais das guildas e dos tribunais corporativos em duas grandes frentes geográficas: no mediterrâneo, com instrumentos jurídicos adaptados do direito romano, e nos mares do norte e báltico, em uma tradição jurídica consuetudinária propriamente germânica. 0 projeto de Goldschmidt de unificação setorial das abordagens romanista e germanista em favor da criação do arcabouço

\footnotetext{
2 WEBER, Max. Die römische Agrargeschichte in ihrer Bedeutung für das Staats- und Privatrecht. Herausgegeben von Jürgen Deininger. Tübingen: Mohr Siebeck, 1986; WEBER, Max. Zur geschichte der Handerlsgesellschaften im Mittelalter. Schriften 1889-1894. Herausgegeben von Gerhard Dilcher und Susanne Lepsius. Tübingen: Mohr Siebeck, 2008. Sobre Weber e a escola histórica do direito, vejam-se MARRA, Realino. Dalla comunità al diritto moderno: la formazione giuridica di Max Weber 1882-1889. Torino: Giappichelli, 1992; SCHIERA, Pierangelo. Max Weber und die deutsche Rechtswissenschaft des 19. Jahrhunderts. In: REHBINDER, Manfred; TIECK, Klaus-Peter (Org.). Max Weber als Rechtssoziologe. Berlin: Duncker \& Humblot, 1987, p. 150-168; DILCHER, Gehard. As raízes jurídicas de Max Weber. Tempo social: Revista de Sociologia da USP, São Paulo, v. 25, n. 1, p. 85-98, 2012; DILCHER, Gehard. Von der Rechtsgeschichte zur Soziologie: Max Webers Auseinandersetzung mit der Historischen Rechtsschule. Juristen Zeitung. Tübingen, ano 62, n. 3, p. 105-112, fev. 2007; BRAND, Arie. Against Romanticism: Max Weber and the Historical School of Law. Australian Journal of Law and Society. North Ryde, v. 1, n. 1, p. 87-100, 1982.
} 
ISSN 1981-3694

(DOI): $10.5902 / 1981369427051$

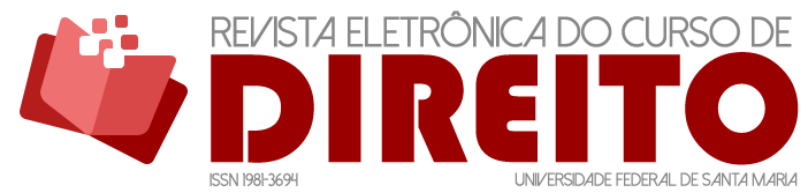

MAX WEBER E A RECEPÇÃO DO DIREITO ROMANO

AleXANDER DE CASTRO

teórico e conceitual do direito comercial foi compartilhado com seus orientandos, dentre os quais o próprio Weber. Situando-se, assim, em uma abordagem à história do direito que se encontrava exatamente entre suas duas principais linhas ${ }^{3}$, Weber teve oportunidade de se instruir nos debates mais profundos de sua época sobre a recepção do direito romano - o ponto fulcral do dissídio entre ambas. Anos depois, já consolidado como sociólogo, Weber teria oportunidade de finalmente elaborar e expressar suas ideias sobre esse momento capital da história do direito moderno.

Tendo já elaborado suas principais ideias metodológicas para as ciências sociais, como o conceito de tipo-ideal, tipos de dominação legítima, formas de racionalidade (formal e material), formas de ação social, etc., a interpretação histórico-sociológica que Weber oferece possui instigantes ideias para elucidar o papel cumprido pela jurisprudência romanista ao longo da formação daquele setor do direito moderno chamada de civil law que prevaleceria em amplas extensões geográfica de diversos continentes. Nas páginas seguintes, serão relembrados os elementos da sociologia weberiana mais importantes para a compreensão de sua interpretação da recepção do direito romano e será identificado o lugar que Weber the atribui em sua visão da sociedade moderna.

\section{A RACIONALIZAÇÃO DO DIREITO: OBJETO DA INVESTIGAÇÃO SOCIOLÓGICA}

Como se sabe, o tema central do pensamento de Max Weber é o fenômeno da racionalização. ${ }^{4}$ De certa forma, o grande objetivo do sociólogo alemão era compreender a singularidade do ocidente moderno enquanto um fenômeno histórico-cultural cuja marca característica consistia precisamente em seu predominante racionalismo. Portanto, o processo

\footnotetext{
3 DILCHER, Gehard. As raízes jurídicas de Max Weber. Tempo social: revista de sociologia da USP, São Paulo, v. 25, n. 1, p. 85-98, 2012. p. 90-92; DILCHER, Gehard. Von der Rechtsgeschichte zur Soziologie: Max Webers Auseinandersetzung mit der Historischen Rechtsschule. Juristen Zeitung, Tübingen, ano 62, n. 3, p. 105-112, fev. 2007. p. 107.

${ }^{4}$ Sobre a questão da racionalização na obra de Weber, vejam-se SELL, Carlos Eduardo. Racionalidade e racionalização em Max Weber. Revista Brasileira de Ciências Sociais, São Paulo, v. 27, n. 79, p. 153-233, jun. 2012 e SCHLUCHTER, Wolfgang. Die Entstehung des modernen Rationalismus: Eine Analyse von Max Webers Entwicklungsgeschichte des Okzidents. Frankfurt am Main: Suhrkamp, 1998. Sobre o desencantamento do mundo, tema ligado umbilicalmente à racionalização, veja-se PIERUCCI, Antônio Flávio. O Desencantamento do Mundo. São Paulo: Ed. 34, 2003.
} 
ISSN 1981-3694

(DOI): $10.5902 / 1981369427051$

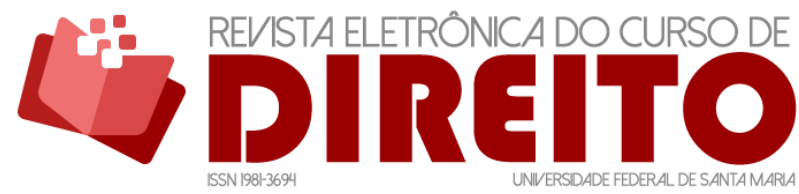

MAX WEBER E A RECEPÇÃO DO DIREITO ROMANO

ALEXANDER DE CASTRO

de racionalização, suas causas e consequências, os fatores que o favoreceram e que o retardaram são estudados por ele nos diversos campos que constituem as áreas temáticas de sua obra, como a religião, a economia, a política, a arte e o próprio direito. De tal forma, o que importa a Weber, no estudo da sociologia do direito, é o processo de racionalização do direito. ${ }^{5}$ É a partir dessa perspectiva que a questão da recepção do direito romano foi abordada.

Quanto a esse processo de racionalização, alguns pontos talvez devam ser esclarecidos. Embora visto por Weber como uma tendência da história humana, a racionalização não é, em sua obra, uma meta histórica objetivamente válida. A história não é teleológica. A tendência à racionalização só se concretiza com a concorrência de inúmeros outros fatores. Além disso, a tendência à racionalização pode tomar inúmeras direções diferentes, diversidade que se deve, justamente, à pluralidade de fatores em ação. Finalmente, a racionalização não é vista por Weber com o otimismo modernista que, ecoando ideias ainda iluministas (como no positivismo de Comte), acreditava que o progresso da razão na história levaria a sociedade a um aprimoramento constante e progressivo. Para Weber, ao contrário, o progresso da racionalização leva o ser humano a dois problemas capitais da modernidade ocidental: a perda do sentido da vida e a perda da liberdade.

O compêndio sistemático de sociologia intitulado Economia e Sociedade contém, na parte referente às sociologias especializadas (como a sociologia da religião e a sociologia do direito), uma estrutura tipológico-sistemática, onde a enorme quantidade de dados históricos das mais diversas épocas é analisado com a finalidade de se identificar determinadas constantes nas relações sociais que possam servir como auxílio na imputação causal concreta de fenômenos individualizados. Esse procedimento se deve à tese weberiana de que o conhecimento nomológico, ou seja, o conhecimento de leis gerais, deve orientar a criação de hipóteses de causas adequadas que ajudem a explicar fenômenos singulares. ${ }^{6}$ Conjugando-se isso com suas conhecidas teses sobre a vinculação da ciência a ideias de valor e a perspectivas, ${ }^{7}$ fica claro por que Weber, na medida em que elege o problema da racionalização como o centro de suas atenções, finaliza a sua sociologia do direito descrevendo as etapas teóricas do processo de

\footnotetext{
${ }^{5}$ Sobre a racionalização do direito em específico, veja-se FREUND, Julien. Die Rationalisierung des Rechts nach Max Weber. In: REHBINDER, Manfred; TIECK, Klaus-Peter (Org.). Max Weber als Rechtssoziologe. Berlin: Duncker \& Humblot, 1987, p. 9-35.

${ }^{6}$ WEBER, Max. A "objetividade" do conhecimento na ciência social e na ciência política. In: WEBER, Max. Metodologia das Ciências Sociais. Parte 1. Tradução de Augustin Wernet. 4. ed. São Paulo: Cortez Editora; Campinas: Editora da Unicamp, 2001, p. 107-154. p. 130.

7 WEBER, Max. A "objetividade" do conhecimento na ciência social e na ciência política. In: WEBER, Max. Metodologia das Ciências Sociais. Parte 1. Tradução de Augustin Wernet. 4. ed. São Paulo: Cortez Editora; Campinas: Editora da Unicamp, 2001, p. 107-154. p. 128.
} 
racionalização. O escalonamento das etapas da racionalização não reivindica qualquer validade objetiva, mas apenas ajuda heuristicamente a organizar a intepretação dos dados empíricos a partir de um declarado interesse teórico de se estudar o direito em relação com os processos de racionalização da modernidade. É por isso também que os fatos históricos elencados nessa parte de Economia e Sociedade, além de não seguirem uma ordem cronológica, aparecerão, na imensa maioria das vezes, como pontos de partida para elaboração de relações teóricas gerais sobre os fenômenos jurídicos. Trata-se, como é sabido, de uma obra de sociologia e não de uma obra de história.

\section{O LUGAR DA RECEPÇÃO NA SOCIOLOGIA DO DIREITO DE WEBER}

O processo de racionalização do direito em Weber é analisado com apoio em uma enorme quantidade de processos históricos concretos, compreendendo a história ocidental e oriental em diversos de seus períodos, de forma a demonstrar uma exuberante e incomparável erudição. Será dispensada aqui a análise minuciosa dos diversos casos apresentados por Weber e as atenções serão centradas diretamente sobre seus aspectos gerais, tais quais analisados por ele. Weber descreve assim as etapas analíticas do processo de racionalização:

O desenvolvimento do direito e do procedimento jurídico, dividido em 'etapas de desenvolvimento' teóricas, conduz à revelação carismática do direito por 'profetas jurídicos' - por meio da criação e aplicação empírica do direito por honoratiores jurídicos (criação de direito cautelar e de direito baseado em precedentes) - , à imposição do direito pelo imperium profano e por poderes teocráticos e, por fim, ao direito sistematicamente estatuído e à 'justiça' aplicada profissionalmente, na base de uma formação literária e formal lógica, por juristas doutos (juristas especializados). As qualidades formais do direito desenvolvem-se nesse processo a partir da combinação de um formalismo magicamente condicionado a uma irracionalidade determinada pela origem em revelações, no procedimento jurídico primitivo, passando, eventualmente, por uma racionalidade material ou não-formal, ligada a um fim e patrimonial ou teocraticamente condicionada, rumo a uma racionalidade e sistemática jurídica crescentemente especializada e, portanto, lógica e, por essa via - sob aspectos puramente externos - , ao progresso da sublimação lógica e do rigor dedutivo do direito e da técnica racional do procedimento jurídico. ${ }^{8}$

${ }^{8}$ WEBER, Max. Economia e Sociedade. Tradução de Regis Barbosa e Karen Elsabe Barbosa. Brasília: Universidade de Brasília; São Paulo: Imprensa Oficial do Estado de São Paulo, 1999. v. 2. p. 143. 
Reitere-se que Weber não vê uma finalidade intrínseca na evolução do direito que o leve obrigatoriamente a uma crescente racionalização. ${ }^{9}$ Se isso aconteceu, foi graças a arranjos históricos específicos. E se Weber assim define seu esquema de interpretação, isso deve-se ao fato de que seu interesse particular reside na compreensão do ocidente moderno enquanto uma singularidade histórico-cultural marcada pelo predominante racionalismo. 0 ápice da racionalidade jurídica é o direito sistematicamente estatuído e baseado em uma formação jurídica especializada, surgido apenas no ocidente. ${ }^{10}$ Fiel a seus parâmetros metodológicos, Weber apenas põe em evidência o aspecto da evolução do direito que se relaciona com o moderno racionalismo ocidental. De tal forma, ele se apressa em deixar claro que essas etapas são apenas teóricas e que, portanto, "nem sempre seguem uma à outra precisamente na ordem da racionalidade crescente, e nem sempre se realizaram todas elas ou sequer existem hoje em dia nem mesmo no Ocidente" ${ }^{11}$. Ao fim e ao cabo, essas etapas teóricas da racionalização do direito constituem apenas um modelo heurístico para interpretação dos dados empíricos na exata medida em que ressaltam o elemento que importa na análise. ${ }^{12}$

Como vimos acima, Weber menciona três etapas teóricas do processo de racionalização do direito, quais sejam: 1) a revelação carismática, mediante profetas jurídicos - por meio da criação e aplicação empírica do direito por honoratiores jurídicos (criação de direito cautelar e de direito baseado em precedentes); 2) a imposição do direito pelo imperium secular e poderes teocráticos; 3) o direito estatuído aplicado por juristas especializados. ${ }^{13}$ A cada uma dessas

\footnotetext{
${ }^{9}$ No mesmo sentido, Katie Argüello: "Por outro lado, a racionalização não aparece na Rechtssoziologie como uma meta final a ser alcançada." ARGÜELLO, Katie. O Ícaro da Modernidade: Direito e Política em Max Weber. São Paulo: Acadêmica, 1997. p. 148.

10 WEBER, Max. Economia e Sociedade. Tradução de Regis Barbosa e Karen Elsabe Barbosa. Brasília: Universidade de Brasília; São Paulo: Imprensa Oficial do Estado de São Paulo, 1999. v. 2. p. 144.

11 WEBER, Max. Economia e Sociedade. Tradução de Regis Barbosa e Karen Elsabe Barbosa. Brasília: Universidade de Brasília; São Paulo: Imprensa Oficial do Estado de São Paulo, 1999. v. 2. p. 144.

12 Talvez por não entender esse aspecto da sociologia jurídica weberiana, Harold Berman qualifique-a como uma historiografia jurídica simplista ("oversimplified”). Veja-se BERMAN, Harold. Max Weber as legal historian. In: TURNER, Stephen (Org.). The Cambridge Companion to Weber. Cambridge: Cambridge University Press, 2000, p. 223-239. p. 223. Além da óbvia observação de que o capítulo VII de Economia e Sociedade não é uma história, mas uma sociologia do direito e que, portanto, procura justamente apenas identificar algumas constantes gerais ilustradas por casos particulares ou contrastadas por contra exemplos, ainda se deve questionar a compreensão de Berman sobre a metodologia de Weber, que nos parece insuficiente para possibilitar-lhe o entendimento do modo weberiano de fazer sociologia e mesmo história. Sobre isso, veja-se BERMAN, Harold. Some false premies of Max Weber's Sociology of Law. Washington University Law Review, Washington, v. 65, n. 4, p. 758-770, jan. 1987. p. 760-761.

${ }^{13}$ Katie Argüello propõe uma divisão diferente, onde "a revelação carismática, mediante os profetas jurídicos" está separada da "criação e aplicação empírica da lei por notáveis [honoratiores] jurídicos". Nos termos do trecho supracitado, parece-nos que Weber vê nos honoratiores algo como uma sub-fase de transição ligada e, de certa forma, pertencente a essa primeira etapa da revelação carismática, ainda que
} 
etapas teóricas vão corresponder formas de racionalismo ou irracionalismo jurídicos que influenciam suas qualidades formais. À primeira corresponde "um formalismo magicamente condicionado a uma irracionalidade determinada pela origem em revelações"; à segunda, "uma racionalidade material ou não-formal, ligada a um fim e patrimonial ou teocraticamente condicionada"; e à terceira, "uma racionalidade e sistemática jurídica crescentemente especializada e, portanto, lógica e, por essa via - sob aspectos puramente externos - , ao progresso da sublimação lógica e do rigor dedutivo do direito e da técnica racional do procedimento jurídico."14

Nesse esquema traçado por Weber para se interpretar o processo de racionalização do direito, a etapa teórica final corresponde ao “direito sistematicamente estatuído e à 'justiça' aplicada profissionalmente, na base de uma formação literária e formal lógica, por juristas doutos (juristas especializados)" ${ }^{15}$. Essa fórmula corresponde precisamente ao civil law, sistema jurídico de base legalista e desenvolvido historicamente a partir de reinterpretações e adaptações do direito romano. Para Weber, é esse sistema jurídico que atinge em seu esquema o grau máximo de racionalidade, o que equivale a dizer o grau máximo de racionalidade formal. ${ }^{16}$

O problema da recepção do direito romano é estudado por Weber no capítulo VII, sobre a sociologia do direito, do segundo volume de Economia e Sociedade. Esse capítulo é dividido em oito parágrafos que preenchem 153 páginas na edição brasileira ${ }^{17}$. A parte relativa à recepção e suas implicações encontram-se no parágrafo sexto desse capítulo. A localização topográfica do texto nos ajuda a iniciar a aproximação ao objetivo de encontrar a função do tema no âmbito dos interesses de Weber.

O citado capítulo sexto tem o título de Direito oficial e estatuto principesco patrimonial. As codificações. Fica fácil, assim, identificar onde está, dentro do esquema teórico da racionalização do direito de Weber, o problema da recepção. Nesse capítulo, Weber estuda a influência do imperium principesco sob o direito comum e, principalmente, sobre a estrutura formal do direito em geral. Estamos, portanto, na segunda etapa, a etapa da imposição do direito pelo imperium secular e poderes teocráticos, à qual corresponde "uma racionalidade

sem as mesmas características. ARGÜELLO, Katie. O Ícaro da Modernidade: Direito e Política em Max Weber. São Paulo: Acadêmica, 1997. p. 153.

14 WEBER, Max. Economia e Sociedade. Tradução de Regis Barbosa e Karen Elsabe Barbosa. Brasília: Universidade de Brasília; São Paulo: Imprensa Oficial do Estado de São Paulo, 1999. v. 2. p. 143.

15 WEBER, Max. Economia e Sociedade. Tradução de Regis Barbosa e Karen Elsabe Barbosa. Brasília: Universidade de Brasília; São Paulo: Imprensa Oficial do Estado de São Paulo, 1999. v. 2. p. 143.

16 WEBER, Max. Economia e Sociedade. Tradução de Regis Barbosa e Karen Elsabe Barbosa. Brasília: Universidade de Brasília; São Paulo: Imprensa Oficial do Estado de São Paulo, 1999. v. 2. p. 143.

17 WEBER, Max. Economia e Sociedade. Tradução de Regis Barbosa e Karen Elsabe Barbosa. Brasília: Universidade de Brasília; São Paulo: Imprensa Oficial do Estado de São Paulo, 1999. v. 2. p. 1-153. 
material ou não-formal, ligada a um fim e patrimonial ou teocraticamente condicionada" ${ }^{18}$. Agora se está em melhores condições de extrair o sentido dado por Weber ao fenômeno da recepção do direito romano.

Localizada a recepção no âmbito das preocupações teóricas de Weber, resta-nos entender qual significado ele the atribui. Mas isso, como foi dito, implica conhecer um pouco mais de suas teses sobre sociologia do direito.

\section{ELEMENTOS DA SOCIOLOGIA DO DIREITO DE WEBER PARA COMPREENDER O PROBLEMA DA RECEPÇÃO}

A racionalização do direito é estudada em relação à produção de suas qualidades formais, como se pode verificar na descrição das suas etapas teóricas. ${ }^{19}$ Assim o objetivo de identificar, no âmbito da sociologia do direito, as características específicas do racionalismo ocidental materializa-se na busca pela definição das características formais do direito moderno, como se pode ver pelo título do último parágrafo do capítulo dedicado à sociologia do direito, que diz expressamente "As qualidades formais do direito moderno" ${ }^{20}$. Portanto, é importante entendermos algumas das considerações de Weber sobre o desenvolvimento das qualidades formais do direito, tais como os mecanismos intelectuais postos utilizados no processo de racionalização e os tipos possíveis de racionalismo e de irracionalismo jurídicos.

A racionalização do direito pode ter lugar através de diversos mecanismos intelectuais. A compreensão da descrição feita por Weber desses mecanismos apresenta certas dificuldades em função, em parte, da própria dificuldade do tema e em parte do método de exposição escolhido pelo autor. Por exemplo, é necessário ressaltar que os vários mecanismos lógicos utilizados no processo de racionalização do direito relacionam-se em um complexo de afinidades e incompatibilidades, no qual um mesmo mecanismo pode agir autonomamente como fator de racionalização em um momento e, em outro, somente como um meio auxiliar para outro

\footnotetext{
18 WEBER, Max. Economia e Sociedade. Tradução de Regis Barbosa e Karen Elsabe Barbosa. Brasília: Universidade de Brasília; São Paulo: Imprensa Oficial do Estado de São Paulo, 1999. v. 2. p. 143.

19 WEBER, Max. Economia e Sociedade. Tradução de Regis Barbosa e Karen Elsabe Barbosa. Brasília: Universidade de Brasília; São Paulo: Imprensa Oficial do Estado de São Paulo, 1999. v. 2. p. 143.

20 WEBER, Max. Economia e Sociedade. Tradução de Regis Barbosa e Karen Elsabe Barbosa. Brasília: Universidade de Brasília; São Paulo: Imprensa Oficial do Estado de São Paulo, 1999. v. 2. p. 142.
} 
mecanismo mais completo e onde formas diferentes de racionalização podem valer-se de um mesmo mecanismo. Eles são os seguintes: 1) A generalização, que - diz Weber - é o tipo mais elementar de manipulação intelectual, significa "a redução das razões que determinam a decisão, no caso concreto, a um ou a vários 'princípios', que são as 'disposições jurídicas'."21 Ela se baseia na seleção de elementos considerados relevantes juridicamente. Essa seleção depende de uma análise dos fatos que Weber chama casuística que, por sua vez, pode também agir autonomamente - isto é, fora do processo de generalização - através do raciocínio analógico ${ }^{22}$; 2) A construção jurídica se realiza através da síntese de conceitos menores que leva à formação de conceitos cada vez mais abrangentes ${ }^{23}$; 3) A sistematização, onde se estabelece uma relação lógica entre componentes obtidos analiticamente dos fatos juridicamente relevantes ou das normas jurídicas para se formar um sistema internamente coeso, concatenado e sem lacunas. No direito moderno, a sistematização repousa na “'interpretação lógica do sentido' tanto das disposições jurídicas quanto do comportamento juridicamente relevante". ${ }^{24}$

A criação e aplicação do direito são analisadas por Weber segundo os binômios racionalidade/irracionalidade e materialidade/formalidade. 0 direito pode ser, assim, formalmente irracional, materialmente irracional, formalmente racional ou materialmente racional. Com base nisso, alguns analistas da sociologia do direito weberiana formularam tiposideais de direito, a saber: o direito irracional-formal, o direito irracional-material, o direito racional-formal e o direito racional-material. ${ }^{25}$ Embora útil, cumpre-se esclarecer que essas quatro formas de criação e aplicação do direito não aparecem na obra de Weber explicitamente como tipos-ideais.

O direito é formalmente irracional quando sua criação e aplicação são feitas por “meios que não podem ser racionalmente controlados" 26 , tais como a consulta a oráculos. A decisão sobre casos concretos deriva da aplicação de métodos que escapam à razão. Trata-se,

21 WEBER, Max. Economia e Sociedade. Tradução de Regis Barbosa e Karen Elsabe Barbosa. Brasília: Universidade de Brasília; São Paulo: Imprensa Oficial do Estado de São Paulo, 1999. v. 2. p. 11.

22 WEBER, Max. Economia e Sociedade. Tradução de Regis Barbosa e Karen Elsabe Barbosa. Brasília: Universidade de Brasília; São Paulo: Imprensa Oficial do Estado de São Paulo, 1999. v. 2. p. 12.

23 WEBER, Max. Economia e Sociedade. Tradução de Regis Barbosa e Karen Elsabe Barbosa. Brasília: Universidade de Brasília; São Paulo: Imprensa Oficial do Estado de São Paulo, 1999. v. 2. p. 12.

${ }^{24}$ WEBER, Max. Economia e Sociedade. Tradução de Regis Barbosa e Karen Elsabe Barbosa. Brasília: Universidade de Brasília; São Paulo: Imprensa Oficial do Estado de São Paulo, 1999. v. 2. p. 12.

${ }^{25}$ A origem da ideia de tipos-ideais de direito parece ser os comentários de Julien Freund à sociologia do direito de Weber. Veja-se FREUND, Julien. Sociologia de Max Weber. Rio de Janeiro: ForenseUniversitária, 1970. p. 184-185. No Brasil, essa interpretação foi difundida por Katie Argüello. Veja-se ARGÜELLO, Katie. O Ícaro da Modernidade: Direito e Política em Max Weber. São Paulo: Acadêmica, 1997. p. 130-132.

26 WEBER, Max. Economia e Sociedade. Tradução de Regis Barbosa e Karen Elsabe Barbosa. Brasília: Universidade de Brasília; São Paulo: Imprensa Oficial do Estado de São Paulo, 1999. v. 2. p. 12. 
sobretudo, das formas de direito revelado. O direito é materialmente irracional quando a decisão depende de avaliações singulares feitas à luz do caso concreto com base em parâmetro meta-jurídicos, tais como sentimentos éticos, de justiça, equidade e até de utilidade. ${ }^{27}$ Trata-se da chamada "justiça do caso concreto", frequentemente chamada por Weber de "justiça de cádi”. ${ }^{28}$

O direito é materialmente racional quando a sua organização atende a finalidades metajurídicas (de ordem ética, utilitária, etc.). Racionalidade formal e material tendem a excluir-se mutuamente no âmbito jurídico (como de resto em qualquer esfera social, segundo a sociologia weberiana), na medida em que as conexões lógicas de sentido das normas têm seu formalismo rompido com as interferências de critérios meta-jurídicos. ${ }^{29}$

O direito é formalmente racional quando "se limita a considerar, no direito material ou no processo, as características gerais unívocas dos fatos." 30 Põe-se de lado aqui as referências a valores meta-jurídicos. ${ }^{31} 0$ direito pode ser racionalizado formalmente de duas maneiras. Há o formalismo de características externas e o formalismo de abstração lógica. ${ }^{32}$ No primeiro, as características juridicamente relevantes manifestam-se sensivelmente, de forma evidente. Trata-se, por exemplo, da exigência de prática de ato simbólico para a validade de um contrato ou de pronúncia de fórmulas processuais para o acesso a remédios judiciais, etc. No segundo, definem-se as características juridicamente relevantes dos fatos e das normas através de uma interpretação lógica do sentido, com base na qual constroem-se "conceitos jurídicos fixos em

\footnotetext{
27 WEBER, Max. Economia e Sociedade. Tradução de Regis Barbosa e Karen Elsabe Barbosa. Brasília: Universidade de Brasília; São Paulo: Imprensa Oficial do Estado de São Paulo, 1999. v. 2. p. 13. Julien Freund afirma que no direito irracional e material "[...] o legislador e o juiz se fundamentam em puros valores emocionais, fora de qualquer referência a uma norma, para consultarem apenas a seus próprios sentimentos." FREUND, Julien. Sociologia de Max Weber. Rio de Janeiro: Forense-Universitária, 1970. p. 184. No entanto, a referência a critérios meta-jurídicos não organizados racionalmente e que não constituem normas gerais é que nos parece ser o determinante para a caracterização desse direito, sem que isto implique, ao contrário do que diz Freund, necessariamente em uma avaliação emocional. Uma avaliação jurídica feita no caso concreto pode atender a uma utilidade e a uma conveniência percebidas empiricamente de forma intelectual (não sentimental), mas sem que sejam elaboradas a ponto de constituir um critério racional com pretensão de validade geral.

${ }^{28}$ Cádi é o juiz muçulmano. Segundo Katie Argüello: "Weber estendeu o termo 'Justiça de Cádi', a partir de seu significado histórico, a toda e qualquer manifestação jurídica que seja por ele considerada espontânea e irracional, ou seja, uma justiça 'salomônica', que exige validez absoluta." ARGÜELLO, Katie. O Ícaro da Modernidade: Direito e Política em Max Weber. São Paulo: Acadêmica, 1997. p. 131.

29 WEBER, Max. Economia e Sociedade. Tradução de Regis Barbosa e Karen Elsabe Barbosa. Brasília: Universidade de Brasília; São Paulo: Imprensa Oficial do Estado de São Paulo, 1999. v. 2. p. 13.

30 WEBER, Max. Economia e Sociedade. Tradução de Regis Barbosa e Karen Elsabe Barbosa. Brasília: Universidade de Brasília; São Paulo: Imprensa Oficial do Estado de São Paulo, 1999. v. 2. p. 13.

31 Veja-se FREUND, Julien. Sociologia de Max Weber. Rio de Janeiro: Forense-Universitária, 1970. p. 184.

32 Seguimos aqui a terminologia utilizada por Katie Argüello. Veja-se ARGÜELLO, Katie. 0 Ícaro da Modernidade: Direito e Política em Max Weber. São Paulo: Acadêmica, 1997. p. 131.
} 
forma de regras rigorosamente abstratas" ${ }^{33}$. No formalismo de características externas, a “sublimação jurídica” ${ }^{34}$ da abstração lógica alcança apenas a casuística. Ao contrário, a tarefa sistematizadora de "coordenar e racionalizar, com os meios da lógica, as regras jurídicas, cuja vigência é reconhecida num sistema, internamente consistente, de disposições jurídicas abstratas" ${ }^{35}$ pertence exclusivamente à abstração interpretadora do sentido do formalismo de abstração lógica, o que o leva a alcançar o mais alto grau de racionalização. Portanto, é precisamente esse tipo que corresponde ao sistema jurídico romano-germânico (civil law), que é descrito por Weber como o correspondente ao "direito sistematicamente estatuído e à 'justiça' aplicada profissionalmente, na base de uma formação literária e formal lógica, por juristas doutos (juristas especializados)." 36

\section{RECEPÇÃO DO DIREITO ROMANO E ABSOLUTISMO: A RACIONALIZAÇÃO DO DIREITO NA DOMINAÇÃO PRINCIPESCA PATRIMONIAL}

O formalismo e irracionalismo, condicionados magicamente na origem das antigas assembleias forenses medievais, são combatidos e contrastados por poderes patrimonialistas autocráticos de dois tipos, a saber, os poderes teocráticos e o imperium principesco. $\mathrm{Na}$ proporção em que racionalizam sua própria administração, esses dois tipos de poderes políticos têm uma tendência imanente a racionalizar o direito, procurando assim eliminar os meios processuais irracionais típicos do processo medieval magicamente condicionado e sistematizar o direito material. Entretanto, a tendência à racionalização dos hierarcas teocráticos e dos príncipes patrimoniais é de índole material, visto que atendem a objetivos éticos ou práticoutilitários. Fica em segundo plano o elemento formal-jurídico e, portanto, qualquer tratamento especificamente "jurídico" do direito, pondo de lado sua racionalização formal e sua calculabilidade, na medida em que o formalismo abstrato da lógica jurídica aparece como um

\footnotetext{
33 WEBER, Max. Economia e Sociedade. Tradução de Regis Barbosa e Karen Elsabe Barbosa. Brasília: Universidade de Brasília; São Paulo: Imprensa Oficial do Estado de São Paulo, 1999. v. 2. p. 13.

${ }^{34}$ WEBER, Max. Economia e Sociedade. Tradução de Regis Barbosa e Karen Elsabe Barbosa. Brasília: Universidade de Brasília; São Paulo: Imprensa Oficial do Estado de São Paulo, 1999. v. 2. p. 13.

35 WEBER, Max. Economia e Sociedade. Tradução de Regis Barbosa e Karen Elsabe Barbosa. Brasília: Universidade de Brasília; São Paulo: Imprensa Oficial do Estado de São Paulo, 1999. v. 2. p. 13.

36 WEBER, Max. Economia e Sociedade. Tradução de Regis Barbosa e Karen Elsabe Barbosa. Brasília: Universidade de Brasília; São Paulo: Imprensa Oficial do Estado de São Paulo, 1999. v. 2. p. 143.
} 
obstáculo a quem quer que busque cumprir finalidades materiais através do direito. É possível, entretanto, que no seio dessas formações políticas surjam racionalizações formais do direito, quando estão presentes as pressões de grupos de interessados em seu caráter formal-jurídico e na consequente calculabilidade de sua aplicação, como foi o caso das classes burguesas entre os séculos XIV e XVIII. ${ }^{37}$

A justiça principesca patrimonial pode ser, para Weber, de tipo estamental ou patriarcal. No tipo estamental, os direitos políticos do príncipe, possuídos como uma forma de patrimônio, encontram-se divididos com um conjunto de súditos privilegiados. Essa circunstância faz com que a administração seja absorvida pela justiça, realizando-se à maneira de um processo judicial, na medida em que qualquer ação administrativa deva levar em conta os direitos de cada detentor de privilégios tradicionais. Segundo Weber, o feudalismo medieval europeu foi o exemplo mais importante e o único plenamente desenvolvido de uma administração patrimonial-estamental. No tipo patriarcal, por outro lado, a aplicação da justiça é que vem a ser absorvida pela atividade administrativa na medida em que é subordinada aos desígnios materiais que a orientam. Tal fato se deve à circunstância de que a produção do direito tende a ser vista como um meio para se atingir os fins éticos, utilitários, etc. desejados pelo príncipe. 0 direito, submetido a desígnios extrajurídicos, passa a ter um caráter nãoformal. Por exemplo, o direito probatório formalmente comprometido tende a ser rompido na medida em que a justiça principesca de caráter patrimonial entra em conflito com os antigos procedimentos magicamente condicionados (e assim sempre formais). Também a rigorosa “máxima processual”, segundo a qual aquilo que não está provado nos autos em conformidade com as regras técnicas do processo não está no mundo, é posta de lado em favor da livre averiguação da verdade, graças à tendência da justiça principesca patrimonialista em direção à “justiça material”. ${ }^{38}$

Como visto, a justiça patriarcal dos príncipes patrimoniais tende a ser racional em um sentido material. Em outras palavras, não é uma racionalização lógica de seus meios de pensamento, mas sim uma tentativa de racionalização de meios jurídicos para a consecução de objetivos materiais, sejam de ordem política, utilitária ou ética. Na dominação principesca patrimonial estamental, pode surgir, em determinadas circunstâncias, um direito formalmente racional. Segundo Weber, pode haver uma coincidência entre os interesses econômicos na

\footnotetext{
37 WEBER, Max. Economia e Sociedade. Tradução de Regis Barbosa e Karen Elsabe Barbosa. Brasília: Universidade de Brasília; São Paulo: Imprensa Oficial do Estado de São Paulo, 1999. v. 2. p. 100.

38 WEBER, Max. Economia e Sociedade. Tradução de Regis Barbosa e Karen Elsabe Barbosa. Brasília: Universidade de Brasília; São Paulo: Imprensa Oficial do Estado de São Paulo, 1999. v. 2. p. 117-122.
} 
ISSN 1981-3694

(DOI): $10.5902 / 1981369427051$

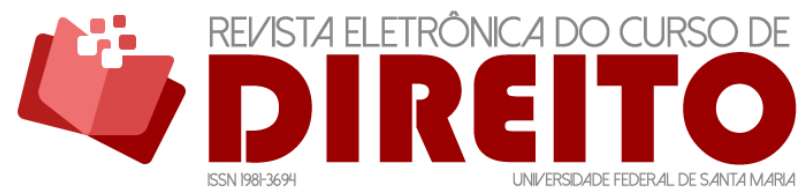

MAX WEBER E A RECEPÇÃO DO DIREITO ROMANO

AleXANDER DE CASTRO

calculabilidade do direito e o interesse do príncipe em aumentar seus poderes frente aos estamentos privilegiados. Assim buscando favorecer esses grupos, ganhando sua lealdade. Com vistas a favorecer seus próprios interesses ficais e políticos, o príncipe pode fazer concessões a um direito que possa ser calculável por parte dos interessados. Então, no âmbito de uma administração patrimonial-estamental, pode ter origem um direito de caráter racional-formal. 0 principal exemplo desse fenômeno são os interesses econômicos burgueses, que necessitavam de "um direito inequívoco, claro, livre de arbítrio administrativo irracional e de perturbações irracionais por parte de privilégios concretos" 39 , que fosse calculável e que garantisse a obrigatoriedade dos contratos. Consequentemente, diz Weber, "a aliança entre interesses principescos e interesses de camadas burguesas" 40 foi uma das mais importantes causas da racionalização formal do direito.

Segundo Weber, a característica mais importante da interferência do imperium principesco no âmbito jurídico é sua tendência para a uniformização e sistematização do direito, o que invariavelmente leva ao interesse pela "codificação". O interesse do príncipe pela “ordem" e "unidade" do reino soma-se ao desejo de "clareza" e uniformidade jurídica dos funcionários incumbidos da administração e aplicação do direito e, ainda, ao interesse das camadas burguesas por "segurança" jurídica. Dito de outra forma, a "codificação" do direito nasce, normalmente, da combinação entre interesses de aquisição burgueses, interesses principescos fiscais e técnico-administrativos e interesses de funcionários. ${ }^{41}$ A "codificação" principesca é um dos portões de entrada da "sistemática" no direito, dividindo espaço com os produtos didático-literários, tais como os "livros de direito" que, muitas vezes, adquiriram força de leis. ${ }^{42}$

A recepção do direito romano ocorreu paralelamente ao desenvolvimento das grandes monarquias principescas patrimoniais da modernidade ocidental. Tratando dos interesses que determinaram a recepção, Weber menciona a posição soberana do monarca na compilação de Justiniano, na medida em que serviam a imperadores e príncipes em sua luta contra outras ordens de poder e às necessidades técnicas do procedimento jurídico (a necessidade de racionalização do processo judicial), às quais os juristas com formação universitária baseada no

\footnotetext{
39 WEBER, Max. Economia e Sociedade. Tradução de Regis Barbosa e Karen Elsabe Barbosa. Brasília: Universidade de Brasília; São Paulo: Imprensa Oficial do Estado de São Paulo, 1999. v. 2. p. 123.

40 WEBER, Max. Economia e Sociedade. Tradução de Regis Barbosa e Karen Elsabe Barbosa. Brasília: Universidade de Brasília; São Paulo: Imprensa Oficial do Estado de São Paulo, 1999. v. 2. p. 123.

41 WEBER, Max. Economia e Sociedade. Tradução de Regis Barbosa e Karen Elsabe Barbosa. Brasília: Universidade de Brasília; São Paulo: Imprensa Oficial do Estado de São Paulo, 1999. v. 2. p. 123.

42 WEBER, Max. Economia e Sociedade. Tradução de Regis Barbosa e Karen Elsabe Barbosa. Brasília: Universidade de Brasília; São Paulo: Imprensa Oficial do Estado de São Paulo, 1999. v. 2. p. 126.
} 
ISSN 1981-3694

(DOI): $10.5902 / 1981369427051$

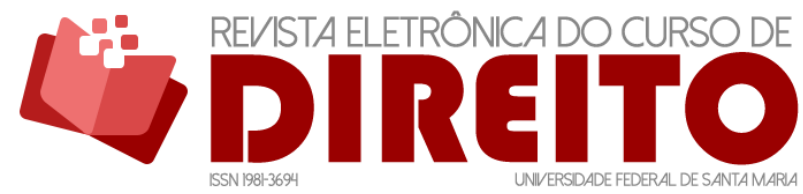

MAX WEBER E A RECEPÇÃO DO DIREITO ROMANO

ALEXANDER DE CASTRO

direito romano estavam aptos a atender. No que diz respeito à existência de interesses econômicos por trás da recepção, Weber afirma cautelosamente que pairam dúvidas que talvez não possam ser cabalmente resolvidas. ${ }^{43}$ Ele nota, porém, que quanto às disposições materiais do direito romano, a recepção pouco interessava à classe burguesa, já que o direito mercantil e o direito dos bens de raiz urbanos medieval "correspondiam muito melhor às suas necessidades" ${ }^{44}$.

Segundo Weber, a vitória do direito romano por quase toda a parte deve-se fundamentalmente à suas qualidades formais, que atendiam melhor à crescente especialização da vida jurídica. As qualidades formais do direito romano são responsáveis, também, pelo fato de a racionalização do direito, no âmbito das monarquias patrimoniais europeias da modernidade, ter tomado um rumo formalista, suplantando assim a tendência a uma racionalização material, inerente às dominações principescas patrimoniais. 0 caráter formalista do direito romano acabou trazendo para a justiça principesca patrimonial europeia aquela específica qualidade formal-jurídica que a caracteriza, distinguindo-se de outras administrações patrimoniais. Esse importante elemento formal-jurídico desvia a justiça europeia de seu caminho natural em direção a um cultivo genuinamente patriarcal do direito. ${ }^{45}$

Weber acrescenta que o direito romano já havia adquirido na época imperial romana um caráter meramente literário. Somava-se a isso, a influência dos conhecimentos filosóficos dos juristas da antiguidade, que acrescentavam na importância do elemento puramente lógico no pensamento jurídico, tornado ainda mais fácil pela desvinculação de qualquer direito sagrado e de qualquer interesse teológico ou ético-material. Entretanto, segundo Weber, o raciocínio jurídico romano antigo manteve sempre um caráter substancialmente indutivo e empírico, em uma índole estritamente analítica que prejudicava a atividade propriamente "construtiva". Apenas durante a recepção, o caráter do raciocínio do direito romano começará a mudar com uma progressiva intensificação do processo de abstração das instituições jurídicas. Para que a recepção fosse possível, era necessário que as instituições jurídicas romanas fossem purificadas dos restos de uma vinculação nacional, para que se elevasse o direito romano a um artefato logicamente abstrato, de forma tal que ele pudesse ser apresentado "como o direito

\footnotetext{
43 WEBER, Max. Economia e Sociedade. Tradução de Regis Barbosa e Karen Elsabe Barbosa. Brasília: Universidade de Brasília; São Paulo: Imprensa Oficial do Estado de São Paulo, 1999. v. 2. p. 127.

44 WEBER, Max. Economia e Sociedade. Tradução de Regis Barbosa e Karen Elsabe Barbosa. Brasília: Universidade de Brasília; São Paulo: Imprensa Oficial do Estado de São Paulo, 1999. v. 2. p. 128.

45 WEBER, Max. Economia e Sociedade. Tradução de Regis Barbosa e Karen Elsabe Barbosa. Brasília: Universidade de Brasília; São Paulo: Imprensa Oficial do Estado de São Paulo, 1999. v. 2. p. 128.
} 
‘logicamente correto’ por excelência” ${ }^{46}$. Só após a recepção, portanto, o direito romano passa a ganhar, graças à abstração lógica, o caráter sistemático que até então the faltava quase completamente. Somente aí - diz Weber - nascem aquelas "categorias puramente sistemáticas", tais como "acordo jurídico" ou "declaração de vontade" 47 . Tudo isso possibilita que, no âmbito do pensamento jurídico, surja a ideia segundo o qual aquilo que o jurista não pode pensar não existe juridicamente.

A combinação entre o desenvolvimento lógico-formal do pensamento jurídico da recepção com a necessidade de aplicar o direito romano a situações fáticas desconhecidas na antiguidade dá origem à ideia do direito enquanto um sistema de normas sem contradições lógicas internas e sem lacunas que devem ser "aplicadas" a fatos. ${ }^{48}$ Weber afirma ainda que, neste caso de racionalização formal do direito, não houve a participação decisiva dos interesses burgueses em um direito calculável, como sói acontecer em processos de desenvolvimento de um direito formal. Nesse caso, ao contrário, o impulso a tal desenvolvimento foi dado por “necessidades intelectuais internas dos teóricos jurídicos e dos doutores por eles formados" ${ }^{49}$.

Entretanto, apesar de alguma circunstancial comunhão de interesses entre os juristas da recepção e as ascendentes monarquias, as formas de direito que emergiam - por um lado - de seu tratamento especializado, cultivado nas escolas que se organizavam em torno ao direito romano, e - por outro - do exercício do poder pelos príncipes patrimoniais estavam em princípio em contradição. Foi durante o "despotismo esclarecido" que o conflito entre ambos - isto é, entre o pensamento jurídico especializado e cultivado em escolas, que caracteriza a recepção, e os interesses dos príncipes patrimoniais - chegou ao seu ponto extremo.

Nesse período, os avanços das administrações centralizadas e o maior ativismo monárquico em todas as esferas, justificada perante o público com discursos paternalistas que atribuíam a príncipes autocráticos a tarefa de governar em favor do "bem-estar geral” ou da "felicidade pública", levaram a reformas legislativas que tendiam a uma racionalização formal do direito, na medida em que a lei era utilizada para atingir finalidades extrajurídicas (econômicas, utilitárias, etc.). O caráter lógico formal da jurisprudência do ius commune originado com a recepção precisava, assim, ser superado, o que - diz Weber - foi tentado até de

\footnotetext{
${ }^{46}$ WEBER, Max. Economia e Sociedade. Tradução de Regis Barbosa e Karen Elsabe Barbosa. Brasília: Universidade de Brasília; São Paulo: Imprensa Oficial do Estado de São Paulo, 1999. v. 2. p. 129.

47 WEBER, Max. Economia e Sociedade. Tradução de Regis Barbosa e Karen Elsabe Barbosa. Brasília: Universidade de Brasília; São Paulo: Imprensa Oficial do Estado de São Paulo, 1999. v. 2. p. 129.

48 WEBER, Max. Economia e Sociedade. Tradução de Regis Barbosa e Karen Elsabe Barbosa. Brasília: Universidade de Brasília; São Paulo: Imprensa Oficial do Estado de São Paulo, 1999. v. 2. p. 129.

49 WEBER, Max. Economia e Sociedade. Tradução de Regis Barbosa e Karen Elsabe Barbosa. Brasília: Universidade de Brasília; São Paulo: Imprensa Oficial do Estado de São Paulo, 1999. v. 2. p. 130.
} 
forma consciente em algumas circunstâncias. Uma particularidade do pensamento filosóficojurídico da época, que muitas vezes antagonizou a prática e mesmo a doutrina especificamente jurídica, foram as utópicas reivindicações de eliminação das mediações especializadas entre o legislador (no caso, o rei e seus altos funcionários) e os cidadãos aos quais se destinavam em última instância as leis. Ainda que utópicas, essas teorias da comunicação direta entre legislador e súditos foram recebidas pelos artífices das reformas legislativas absolutistas em vários lugares, o que obviamente acentuava o conflito com o pensamento jurídico de especialistas e sua linguagem cifrada. ${ }^{50}$

Weber menciona o Allgemeines Landrecht für die Preußischen Staaten (referido como "Direito Geral" prussiano na tradução em português de Economia e Sociedade) como exemplo de direito materialmente racionalizado típico de um patriarcalismo voltado ao "bem-estar". ${ }^{51}$ Dentre suas várias características distintivas, esse código insurgia-se contra a criação jurisprudencial do direito e, portanto, contra o poder da casta jurídica de determinar o direito frequentemente à revelia dos objetivos do legislador. Buscando eliminar todo e qualquer espaço para ela, cobrindo diligentemente os espaços em que a lacuna ou a falta de clareza pudesse requerer a complementação jurisprudencial, acabava-se por desenvolver uma casuística legal extremamente minuciosa na tentativa de criar uma codificação "exaustiva”. Entretanto, segundo Weber, o experimento malogrou devido a um concurso de causas. Em primeiro lugar, a tendência à justiça material em detrimento do formalismo causava inúmeras vezes a falta de precisão. Como consequência, embora em grande parte a eliminação da criação do direito por juristas profissionais tenha sido atingida, viu-se ao mesmo tempo completamente frustrada a expectativa de instruir o público diretamente nos assuntos jurídicos, coisa que jamais seria viável através de uma obra legislativa de numerosos volumes e com os milhares de parágrafos necessários para cobrir as inúmeras situações que deveriam ser regulamentadas por esse direito que se pretendia “completo". Por fim, com o intuito de amenizar a imprecisão inerente ao casuísmo legislativo, manteve-se a vinculação ao acervo conceitual e à metodologia do direito romano, cuja linguagem era obviamente inacessível ao público leigo. Fracassava, assim, a tentativa de emancipar o público da mediação dos advogados e de outros práticos jurídicos profissionais. $^{52}$

50 WEBER, Max. Economia e Sociedade. Tradução de Regis Barbosa e Karen Elsabe Barbosa. Brasília: Universidade de Brasília; São Paulo: Imprensa Oficial do Estado de São Paulo, 1999. v. 2. p. 130.

51 WEBER, Max. Economia e Sociedade. Tradução de Regis Barbosa e Karen Elsabe Barbosa. Brasília: Universidade de Brasília; São Paulo: Imprensa Oficial do Estado de São Paulo, 1999. v. 2. p. 131.

52 WEBER, Max. Economia e Sociedade. Tradução de Regis Barbosa e Karen Elsabe Barbosa. Brasília: Universidade de Brasília; São Paulo: Imprensa Oficial do Estado de São Paulo, 1999. v. 2. p. 131. 
A contradição entre o racionalismo material patrimonial e o desenvolvimento do pensamento jurídico-formal fez com que - segundo Weber - uma das principais consequências da codificação prussiana tenha sido fazer com que o jurista de formação especializada se voltasse ao direito romano e, por influência do nacionalismo, em parte também ao direito alemão antigo, desligando-se da prática para, com o apoio da metodologia histórica, procurar reconstruir a substância "pura", original, de ambos. ${ }^{53}$ Eis aí, indicava Weber, as origens da escola histórica do direito na Alemanha, em suas vertentes romanista e germanista. Para o direito romano, a consequência desse tratamento historiográfico teria sido a eliminação de todas as transformações que o adaptaram a partir da recepção às necessidades sociais e econômicas de então. O Usus Modernus Pandectarum (uso moderno das pandectas) caiu, assim, no esquecimento. O resultado é que o direito romano passava, portanto, a não corresponder mais aos interesses comerciais modernos. A perda do interesse prático sobre o direito romano deixava “inteiramente livre o caminho para a lógica jurídica abstrata"54. 0 racionalismo científico, cuja superação os representantes da escola histórica reivindicavam ao deixarem de lado o direito natural, era então apenas deslocado.

Entretanto, segundo Weber, a realização de uma nova sistemática puramente lógica do direito romano antigo e a sublimação jurídica estritamente formal das instituições provenientes do direito germânico fracassaram. Apenas as partes referidas ao direito comercial puderam sofrer uma sistematização científica e codificadora graças à interferência de necessidades econômicas prementes e óbvias. Entretanto, ao cabo, a codificação do direito civil alemão acabou sendo realizada por uma das vertentes do historicismo jurídico alemão, isto é, pelo conceitualismo abstrato dos pandectistas. Que esta codificação tenha sido o produto de uma sistematização e sublimação jurídicas que coroava o trabalho de longas décadas de depuração histórica, é algo que Weber põe em questão ao afirmar que, após sete décadas de hegemonia da escola histórica, a tarefa de uniformização do direito civil alemão foi realizada por uma classe de juristas "dividida em si", de "má vontade" e "num estado de ânimo muito pouco preparado para ela". ${ }^{55}$

\footnotetext{
${ }^{53}$ WEBER, Max. Economia e Sociedade. Tradução de Regis Barbosa e Karen Elsabe Barbosa. Brasília: Universidade de Brasília; São Paulo: Imprensa Oficial do Estado de São Paulo, 1999. v. 2. p. 132.

${ }^{54}$ WEBER, Max. Economia e Sociedade. Tradução de Regis Barbosa e Karen Elsabe Barbosa. Brasília: Universidade de Brasília; São Paulo: Imprensa Oficial do Estado de São Paulo, 1999. v. 2. p. 132.

55 WEBER, Max. Economia e Sociedade. Tradução de Regis Barbosa e Karen Elsabe Barbosa. Brasília: Universidade de Brasília; São Paulo: Imprensa Oficial do Estado de São Paulo, 1999. v. 2. p. 132.
} 


\section{CONCLUSÃO}

As poucas páginas dedicadas por Weber ao tema da recepção podem enganar quanto à importância atribuída por ele a esse importantíssimo episódio da história do direito. Na verdade, embora Weber não faça qualquer tipo de história da recepção, o tratamento que ele the dispensa singulariza-a como um momento chave da inflexão do desenvolvimento específico do racionalismo formal no direito ocidental. A recepção do direito romano e a formação de um tipo específico de tradição literária em torno dele alterou substancialmente os caminhos seguidos pelas dominações políticas principescas patrimoniais patriarcais - as monarquias absolutistas - da Europa no campo da produção e aplicação do direito.

A racionalização do direito nessas condições políticas - ou seja, no âmbito de uma estrutura principesca patrimonialista patriarcal - deveria, pela natureza de suas condicionantes políticas, desenvolver-se em sentido material, mas foi redirecionada pela influência do ius commune a partir da recepção. A literatura jurídica do direito comum (ou seja, sua jurisprudência no sentido original da expressão) construiu-se através do formalismo lógicoabstrato, baseado na interpretação lógica do sentido, que acabou dominando quase completamente o pensamento jurídico europeu-continental, mesmo aquele que não se baseava em fontes jurídicas romanistas. Foi precisamente a força com que esse raciocínio racionalista formal se impôs sobre a comunidade de especialistas que constituiu um dos principais entraves para as pretensões de racionalização material do direito por parte dos príncipes patrimoniais. Ao marcar tão profundamente o pensamento jurídico do continente a ponto de fornecer as bases para o parâmetro do que viria a ser ali considerada ciência do direito, o ius commune forçou-o a seguir pelo caminho do formalismo de abstração lógica baseado na interpretação lógica do sentido. É precisamente esse formalismo de abstração lógica baseado na interpretação lógica do sentido que Weber considera como a mais racionalizada forma de raciocínio jurídico e, portanto, constituiria um dos elementos mais importantes do moderno direito estatuído e aplicado por profissionais. Portanto, na análise weberiana, a base de raciocínio característica da jurisprudência do direito comum impôs-se, ao menos parcialmente por sua força intrínseca, à tradição da civil law do direito moderno. 


\section{REFERÊNCIAS}

ARGÜELLO, Katie. O Ícaro da Modernidade: Direito e Política em Max Weber. São Paulo: Acadêmica, 1997.

BERMAN, Harold. Max Weber as legal historian. In: TURNER, Stephen (Org.). The Cambridge Companion to Weber. Cambridge: Cambridge University Press, 2000, p. 223-239.

BERMAN, Harold. Some false premies of Max Weber's Sociology of Law. Washington University Law Review, Washington, v. 65, n. 4, p. 758-770, jan. 1987.

BRAND, Arie. Against Romanticism: Max Weber and the Historical School of Law. Australian Journal of Law and Society, North Ryde, v. 1, n. 1, p. 87-100, 1982.

DILCHER, Gehard. As raízes jurídicas de Max Weber. Tempo social: revista de sociologia da USP, São Paulo, v. 25, n. 1, p. 85-98, 2012.

DILCHER, Gehard. Von der Rechtsgeschichte zur Soziologie: Max Webers Auseinandersetzung mit der Historischen Rechtsschule. Juristen Zeitung, Tübingen, ano 62, n. 3, p. 105-112, fev. 2007.

FREUND, Julien. Die Rationalisierung des Rechts nach Max Weber. In: REHBINDER, Manfred; TIECK, Klaus-Peter (Org.). Max Weber als Rechtssoziologe. Berlin: Duncker \& Humblot, 1987, p. 9-35.

FREUND, Julien. Sociologia de Max Weber. Rio de Janeiro: Forense-Universitária, 1970.

LEPSIUS, M. Rainer. "Economia e sociedade": a herança de Max Weber à luz da edição de sua Obra completa (MWG). Tempo social: revista de sociologia da USP. São Paulo, v. 25, n. 1, p. 137-145, 2012.

MARRA, Realino. Dalla comunità al diritto moderno: La formazione giuridica di Max Weber 1882-1889. Torino: Giappichelli, 1992.

PIERUCCI, Antônio Flávio. O Desencantamento do Mundo. São Paulo: Ed. 34, 2003.

SCHIERA, Pierangelo. Max Weber und die deutsche Rechtswissenschaft des 19. Jahrhunderts. In: REHBINDER, Manfred; TIECK, Klaus-Peter (Org.). Max Weber als Rechtssoziologe. Berlin: Duncker \& Humblot, 1987, p. 150-168.

SCHLUCHTER, Wolfgang. Die Entstehung des modernen Rationalismus: Eine Analyse von Max Webers Entwicklungsgeschichte des Okzidents. Frankfurt am Main: Suhrkamp, 1998.

SELL, Carlos Eduardo. Racionalidade e racionalização em Max Weber. Revista Brasileira de Ciências Sociais, São Paulo, v. 27, n. 79, p. 153-233, jun. 2012. 
ISSN 1981-3694

(DOI): $10.5902 / 1981369427051$

WEBER, Max. A ciência como vocação. In: WEBER, Max. Ciência e Política: duas vocações. Tradução de Leonidas Hegenberg e Octany Silveira da Mota. 12. ed. São Paulo: Cultrix, 2004, p. 17-52.

WEBER, Max. A "objetividade” do conhecimento na ciência social e na ciência política. In: WEBER, Max. Metodologia das Ciências Sociais. Parte 1. Tradução de Augustin Wernet. 4. ed. São Paulo: Cortez Editora; Campinas: Editora da Unicamp, 2001, p. 107-154.

WEBER, Max. Die römische Agrargeschichte in ihrer Bedeutung für das Staats- und Privatrecht. Herausgegeben von Jürgen Deininger. Tübingen: Mohr Siebeck, 1986.

WEBER, Max. Economia e Sociedade. Tradução de Regis Barbosa e Karen Elsabe Barbosa. Brasília: Universidade de Brasília; São Paulo: Imprensa Oficial do Estado de São Paulo, 1999. v. 2.

WEBER, Max. Zur geschichte der Handerlsgesellschaften im Mittelalter. Schriften 1889-1894. Herausgegeben von Gerhard Dilcher und Susanne Lepsius. Tübingen: Mohr Siebeck, 2008.

\section{COMO FAZER A REFERÊNCIA DO ARTIGO (ABNT):}

CASTRO, Alexander Rodrigues de. Max Weber e a recepção do direito romano. Revista Eletrônica do Curso de Direito da UFSM, Santa Maria, RS, v. 12, n. 3, p. 889-909, dez. 2017. ISSN 1981-3694. Disponível em:

<https://periodicos.ufsm.br/revistadireito/article/view/27051>. Acesso em: dia mês. ano. doi: http://dx.doi.org/10.5902/1981369427051. 